\title{
Methods to improve seed germination of purple coneflower (Echinacea purpurea (L.) Moench).
}

\author{
U. R. Bishnoi, J.E. Willis, and S Rao Mentreddy \\ Department of Natural Resources and Environmental Sciences, Alabama A \& M University, \\ Normal, AL. USA
}

\begin{abstract}
Purple coneflower (Echinacea purpurea (L.) Moench) is a wild flower plant and has gained economic importance both, as a medicinal and ornamental plant. However, because of variation in seed dormancy it often gives erratic germination leading to poor field stand, limiting its production. The objectives of this study were to evaluate the performance of germination enhancing treatments 1) mechanical scarification; 2) PEG-8000 priming; 3) ethylene (ethaphon); 4) putrescine; and 5) a combination treatment of pre-chilling with ethephon and PEG-8000. All seed lots tested showed wide variation in the level of dormancy. Ethephon significantly increased early germination of all seed lots tested. PEG 8000 at a water potential of $-0.5 \mathrm{mPa}$ and mechanical scarification significantly decreased days to germination and increased total germination of dormant seed lot. Putrescine at $0.25,0.50$ or $1.0 \mathrm{mM}$ rates had no effect on germination.
\end{abstract}

\section{INTRODUCTION}

The genus Echinacea of family Asteraceae has nine species that are indigenous to North America and only three of them Echinacea purpurea L. Moench (purple coneflower), E. pallida (Nutt.) Nutt. (pale coneflower), and $\mathrm{E}$. angustifolia DC (prairie coneflower), are known for their economic importance (AAFRD, 1997). Native Americans have used Echinacea stem and root extracts as painkiller, snakebite treatment, and cold remedy for centuries (Wilson, 2000). More recently, Echinacea has been used for its antibiotic and immunostimulatory properties, especially by the European community (Kindscher, 1989). In a survey conducted in Germany, over 280 preparations including ointments, lotions, and toothpaste containing extracts of Echinacea spp. were identified (Adam, ATTRA, 2002). There is an increasing demand for Echinacea in the United States. During 1999, sales of Echinacea extracts at food, drug, and mass merchandise markets accounted for $\$ 29 \mathrm{~m}$ and a 9 percent market share (Coltrain, 2001).

Echinacea purpurea, easy to cultivate in the southeastern US, has been reported to contain high concentrations of beneficial phytochemicals (AAFRD, 1997). Echinacea purpurea, is distributed from Georgia to Louisiana in the South to lowa in the Midwest (Radford et al., 1968). Echinacea purpurea production practices in United States are highly variable because of the high cost of seed and poor seedling emergence. It has been reported that direct field seeding of $E$. purpurea often results in low and unacceptable stand count. Smith-Jochum and Albrecht
(1987) conducted a field study on E. purpurea and found that emergence was less than 10\%. The principle reason for low emergence of $E$. purpurea seed is a partially permeable inner membrane that may impose seed dormancy (Atwater, 1980). The methods of asexual propagation using root cutting, micropropagation using tissue culture techniques and leaf tissues are costly, laborious, require specialized equipment, and produce relatively few propagules per plant (Koroch et al., 2002). Therefore, propagation through use of seed is currently the most common method for commercial production of $E$. purpurea, however its low seed germination is causing a significant limitation to large scale seed production. Researchers, herb growers, and nursery operators commonly find highly variable germination among the E. purpurea population (Pill and Haynes, 1996), and poor seedling establishment (Atwater, 1980). Greenhouse growers often allow 45-60 days for $E$. purpurea seed to germinate and the final germination may still not exceed $20-30 \%$. Numerous studies using light, gibberellic acid, and chilling have been undertaken to overcome dormancy of purple coneflower seeds with some positive effects. The effects of scarification, use of ethylene, putrescine, and priming with PEG 8000 to improve germination of purple coneflower and testing its seed through use of Seed Testing Rules (AOSA, 2001) have not been extensively tried. Therefore, the objective of this research was to evaluate effects of mechanical scarification, ethephon, putrescine, and priming with 
PEG 8000 on breaking seed dormancy or to enhance E. purpurea seed germination.

\section{MATERIAL AND METHODS:}

Seed Source: Four seed lots (three CM 14, 19249, and ER14 from Holland and one 10270 from seed companies in US) were obtained. Each lot consisted of 15 grams of vacuum packed clean seed in foil seed packets.

Seeds from each of these lots were tested for dormancy using TZ $(2,3,5$ triphenyl- $2 \mathrm{H}$-tetrazolium chloride) staining procedure outlined for the seeds of family Asteraceae in the AOSA Tetrazolium Testing Handbook (AOSA, 2000). After staining, the percentage of viable seeds was examined under $10 \mathrm{X}$ magnification and were evaluated following the procedure of Peters and Lanham (2000). The level of dormancy was determined as the difference between percent seed viability and percent standard germination. Holland grown seeds exhibited the least dormancy problem whereas the US grown lot 10270 exhibited the highest. To overcome this high dormancy, the performance of following germination enhancing treatments on seeds of each lot were evaluated.

Mechanical Scarification: Based on a trial using locally produced seeds, optimum time of scarification was determined as 120 seconds. Four replications of 50 -seeds each from each seed lot were scarified for 120 seconds. Following the treatment, a standard germination as per AOSA guidelines was conducted on scarified seed in comparison with nonscarified to evaluate effect of scarification on earliness and the total seed germination from each lot.

Priming Seed with PEG 8000: In this experiment, four treatments, water only as control, and three aqueous PEG 8000 solutions with osmotic potential of $-0.5,-1.0$, and $-1.5 \mathrm{mPa}$ were tested (Bishnoi et al., 1997). Four 50-seed replicates from each lot were placed in fisher $100 \mathrm{~mm}$ petri dishes with P-8 filter paper in each to which $10 \mathrm{ml}$ PEG 8000 solution was added. After keeping petri dishes at $5^{\circ} \mathrm{C}$ for $24 \mathrm{hrs}$, the filter papers and seeds were placed in a $70 \mathrm{~mm}$ Buchner funnel (Sigma chemicals) inserted into a $1 \mathrm{~L}$ filter flask and vacuum filtered in three $10 \mathrm{ml}$ volumes of distilled water to remove the priming agent. After filtration seeds were tested for standard germination using AOSA guidelines.

Ethephon Pre-treatment: Four replications of 50 seeds each were primed at $5^{\circ} \mathrm{C}$ for 24 hours in $10 \mathrm{ml}$ of 100,300 , or $500 \mathrm{ppm}$ solutions of Pistill brand Ethephon solution prepared from the stock solution of $500 \mathrm{ppm}$ obtained by adding $13.21 \mathrm{ml}$ of Florel brand
Pistill (Rhone-Poulenc, Troy, NY) to one litter of water. After priming, seeds were vacuum filtered and tested for standard germination.

Putrescine Pre-Treatment: Putrescine priming solution was prepared by $0.25,0.50$, and $1.0 \mathrm{mM}$ of dihydochloride putrescine (Sigma Chemicals) in $10 \mathrm{ml}$ of water. Four replications of 50 seeds from each seed lot were primed with Putrescine solution at the appropriate treatment level and then tested for standard germination in comparison to control.

Treatment with PEG $\mathbf{8 0 0 0}$ and Ethephon Mixture: In this experiment seeds were treated with $100 \mathrm{ppm}$ ethephon mixed in a $-1.0 \mathrm{mPa}$ solution of PEG 8000 at $5^{\circ} \mathrm{C}$ for 1,3 , and 7 days. After the treatment, seeds were vacuum filtered and tested for standard germination.

All standard germination tests were conducted at 20$30^{\circ} \mathrm{C}$ in petri dishes with Fisher P-8 filter paper. Seedlings with fully developed cotyledon leaves and well developed radicle were counted as normal on 4,8 , and 12 days after planting. The results have been expressed as percentage of the total seed planted.

\section{RESULTS AND DISCUSSION:}

Mechanical Scarification: Seeds from different lots when scarified for 120 seconds, showed significant improvement in final percent germination. The dormant seed lot 10270 gave significantly early and higher total percent germination (Table 1) in comparison to seeds of other lots.

PEG 8000 priming Treatment: Priming with PEG 8000 induced water potentials of -0.5 and $-1.0 \mathrm{mPa}$ and it significantly increased total percent germination in dormant seed lot 10270 (Table 1). Seed tested from each lot at $-1.5 \mathrm{mPa}$ tended to reduce seed germination compared to that at lower concentrations, but the differences were not significant.

Ethephon Pre-treatment: For all the seed lots, ethephon application significantly increased early germination but not final percent germination (Table 2). Additionally, in seed from lots 10270 and CM 14, 300 and 500ppm ethephon application significantly increased early percent germination, while $100 \mathrm{ppm}$ treatment was not significantly different from control. In seed lots ER-15 and 19249, 100, 300, and 500ppm ethephon application significantly increased early percent germination. 
Agric. Biol. J. N. Am., 2010, 1(3): 185-188

Table. 1. Standard germination of four seed lots of Echinacea purpurea following mechanical scarification and PEG 8000 priming.

\section{Seed Lots}

CM 14

Day of Count

Treatment

4

12

Day of Count

4

12

Mechanical Scarification
$48 \mathrm{a}$

\begin{abstract}
$69 a$
\end{abstract}
$46 a$

$69 a$

$$
41 a
$$

$80 a$

$$
46 \mathrm{~b}
$$

0.756

0.01

$84 a$

0.454

0.103

19249

ER-15

F-value

0.934

PEG 8000

Control

$-0.5 \mathrm{mPa}$

$$
19 a
$$

$87 a \quad 33 a$

$80 a$

$88 \mathrm{a} \quad 60 \mathrm{~b}$

$96 \mathrm{~b}$

$85 a \quad 53 a b$

$93 \mathrm{~b}$

83a $31 a \quad 82 a$

$17 a$

0.65

$0.65 \quad 0.018$

0.006
Day of Count

12

$\begin{array}{lll}4 & 12 & 4\end{array}$

$-1.5 \mathrm{mPa}$

0.553

$\begin{array}{cccc}63 a & 89 a & 51 a & 64 a \\ 75 a & 97 b & 56 a & 69 a \\ 0.103 & 0.001 & 0.6 & 0.087\end{array}$

$62 a$

$71 \mathrm{a}$

$47 a b$

$25 b$

0.01

$\begin{array}{ccc}94 a & 53 a & 86 a \\ 98 a & 46 a b & 92 a \\ 83 a & 43 a b & 96 a \\ 75 a & 26 b & 43 a \\ 0.27 & 0.026 & 0.4775\end{array}$

For statistically significant treatments at $\alpha=0.05$, numbers followed by the same letter are not significant according

Table. 2. Standard germination (\%) of four seed lots of Echinacea purpurea following 24 hour conditioning with to Tukey's Honest Significant Difference. ethephon (ppm) and putrescine $(\mathrm{mM})$ at $5^{\circ} \mathrm{C}$.

\section{Seed Lots}

CM 14

Day of Count

10270

\begin{abstract}
Day of Count
\end{abstract}
8

Ethephon

Control

100 ppm

300 ppm

500 ppm

F-value

Putrescine

Control

$0.25 \mathrm{mM}$

$0.50 \mathrm{mM}$

$1.0 \mathrm{mM}$

F-value

$\begin{array}{cccccc}25 a & 84 a & 88 a & 31 a & 68 a & 80 a \\ 40 a b & 71 a & 86 a & 46 a b & 76 a & 85 a \\ 45 b & 75 a & 86 a & 50 b & 77 a & 88 a \\ 44 b & 78 a & 85 a & 54 b & 73 a & 83 a \\ 0.01 & 0.26 & 0.27 & 0.01 & 0.87 & 0.17\end{array}$


In all four seed lots, 300 and 500-ppm ethephon increased the number of seedlings with shortened, stubby cotyledons and radicals. These abnormal structures were not detected at the 100ppm ethephon level showing that ethephon application did not increase final percent germination in any of the four seed lots.

The ethephon findings reported here corroborate with earlier research of Kochankov et al., (1998) and Feghahtati and Reese (1994). Ethephon tended to increase final percent germination of the dormant seed only. As such, one could expect ethephon to impact the final percent germination of dormant seeds positively in a manner similar to its effect on stressed seeds.

Putrescine pre-treatment: None of the putrescine treatments significantly increased the early (on $4^{\text {th }}$ day count after planting) nor final (on $12^{\text {th }}$ day count after planting) percent seed germination, however the inclusion of $0.25 \mathrm{mM}$ and $0.5 \mathrm{mM}$ putrescine did tend to increase the final percent germination of the dormant seed lot-10270 (Table 2). The differences in germination, however, were not statistically significant.

The failure of the putrescine pre-treatment of seed to enhance germination of the four seed lots could be due to the lack of dormancy in the three Holland seed lots tested. Similar findings have been reported in sunflower, (Helianthus annus) where $1 \mathrm{mM}$ putrescine did not affect germination of non-stressed seeds, but resulted in a four-fold increase in final percent germination of seeds stressed with $200 \mathrm{mM} \mathrm{NaCl}$ (Tekin and Bozcuk, 1998).

PEG 8000 with Ethephon Treatment: In this study, seed lots were pre-chilled for 1,3 , and 7 days with a combination of $100 \mathrm{ppm}$ and $-0.5 \mathrm{mPa}$ osmotic potential. On seed lot CM 14, pre chilling time and PEG 8000 water potential had no effect on 4,8 or 12 days of seed germination. Use of $100 \mathrm{ppm}$ ethephon significantly increased the early germination in seed lot 10270 . In the seed lot CM 14, the effects of pre-chilling time, PEG 8000 or interactions between main treatments were not significant. In seed lot 19249, ethephon application significantly increased the early percent germination as well as the total final percent germination on $8^{\text {th }}$ day. In seed lot ER 15, ethephon application, PEG 8000, and significantly increased the early and final percent germination. Ethephon $x$ PEG interaction was also significant in increasing early and final percent germination in this lot. .

\section{CONCLUSIONS:}

The results of this study showed that seed dormancy is variable in commercially available E. purpurea seed lots. The germination in lots with high dormancy can significantly start earlier and can be enhanced by scarification for 120 seconds as well as with application of Ethephon at the rate of $100 \mathrm{ppm}$ or priming seed with PEG 8000.

\section{REFERENCES:}

AAFRD (Alberta Agriculture Food and Rural Development). (1997). Commertial Echinacea http://www.agric.gov.ab.ca/agdex/100/188 830-8.html) verified oct.10 2002.

Adam, K. L. (2002). Echinacea as an alternative crop. ATTRA (http://ATTRA.org) verified Oct, 10, 2002. Agricultural Experiment station. Ser. MF-2532. Kansas State University, Manhattan, KS.

Association of official Seeds Analysts. (2001). Rules for testing Seeds. AOSA, Beltsville, MD. Association of official Seeds Analysts. 2002. Tetrazolium Testing Handbook. AOSA, Beltsville, MD.

Atwater, B. R. (1980). Germination, dormancy, and morphology of the seeds of herbaceous ornamental plants. Seed Sci. and Tech. 8: 523-73.

Bishnoi, U.R., Garton, S. and Maiga A. (1997). Germination of sorghum cultivars at different $\mathrm{pH}$ levels and moisture potentials. Annals of Arid Zone. 36: 31-36.

Coltrain, D. (2001). Economic issues with Echinacea. Kansas State University.

Feghahati, S.M. and R. N. Reese. (1994). Ethylene-, light-, and prechill- enhanced germination of Echinacea angustifolia Seeds. J. Amer. Hort. Sci. 4: 853-58.

Kindscher, K., (1989). Ethnobotanyof purple coneflower. Echinacea anustifolia and other Echinacea species. Economic Botany. 43:498-507.

Kochankov, V.G., M. Grzesik, M. Chojnowski and J. Nowak. (1998). Effect of temperature, growth regulators, and other chemicals on Echinacea purpurea (L.) Moench seed germination and seedling survival. Seed Sci. and Tech. 26: $547-54$.

Koroch, A., H. R. Juliana, J. Kapetyn, and J. E. Simon. (2002). In vitro regeneration of Echinacea purpurea from leaf explant. Plant Cell Tissue and Organic Cell Culture. 69: 7983.

Peters, J. and Lanham, B. (2000). Tetrazolium Testing Handbook. Contribution 29. Association of Official Seed Analysts.

Pill, W. G. and J.G. Haynes. (1996). Gibberellic acid during priming of Echinacea purpurea (L. ) Moench Seed improves performance after seed storage. J. of Hort. Sci. 71: 287-95.

Radford, A.E., H.E. Ahles, and C. R. Bell. (1968). Manual of the vascular flora of the Carolina's. University of North Carolina Press. Chappal Hill, NC.

Smith-Jochum C.C. and M.L. Albrecht. (1987). Field establishment of three Echinacea species for commercial production. ACTA Horticulturae. 208: 115-18.

Tekin, F. and S. Bozcuk. (1998). Effects of salt and exogenous putrescine on seed germination and early seedling growth of Helianthus annus L. var. Santafe. Turkish Journal of Botany. 22: 331-40.

Wilson, D. (2000). Wild about Echinacea. Seed World 138: 2226 